\title{
SEA ICE MANAGEMENT FOR OIL AND GAS PLATFORMS IN THE BOHAI SEA
}

\author{
ZHANG Da-yong, Prof. Dr. \\ YU Song-song, Ph. D. \\ WANG Yanlin, Prof. Dr. \\ YUE Qian-jin,Prof. Dr. \\ Dalian University of Technology, China
}

\begin{abstract}
Bohai is a typical marginal oil field in an ice region, where most of the oil and gas platforms are economical. Sea ice is the main factor that affects the safety of oil and gas platforms in Bohai. Due to the complexity of the ice load and ice-induced vibrations, there are large security risks when developing Bohai oil and gas in the winter. It is difficult to ensure the safe production of oil and gas in winter using existing sea ice disaster warning technologies. Based on winter oil and gas production in the Bohai Sea's Liaodong Bay, a set of suitable sea ice management systems is proposed in this paper. These systems integrate sea ice monitoring, risk assessment and risk prediction technologies. Based on the risk warning system, an ice management model of a Bohai ice platform has been put into practice, which ensures the safe production of the platform in winter.
\end{abstract}

Keywords: Bohai; Sea ice management; Ocean platform; Ice-induced vibration; Ice risk prediction

\section{INTRODUCTION}

With technological developments and the constant demand for energy, the exploitation of offshore oil and gas has been extended into ice regions. In open waters, only conventional marine environmental loads (winds, waves and currents) have been considered in offshore oil and gas exploitation and structural design. In ice regions, however, both for marine engineering structure design and resource drilling, development must confront the problems caused by sea ice.

In most ice regions, the threats to marine resources development from sea ice are much larger than those for waves and winds. Throughout history, accidents have occurred due to sea ice. In the 1980s, lighthouses in the Gulf of Bothnia experienced ice-induced vibrations, and one collapsed[1]. Over the same period, Molikpaq's foundation, a sand base caisson structure in the Beaufort Sea, was liquefied due to iceinduced vibrations[2]. In 1969, a Bohai oil platform collapsed due to a severe sea ice disaster.
In the late 1980s, significant ice-induced vibrations affected more than a dozen platforms in the Bohai Sea's Liaodong Bay and imposed large security risks on oil and gas exploitation during the winter. During the winter of 2000, ice-induced vibrations caused pipeline fatigue fracturing and loosened a flange on the JZ20-2MSW platform. Continuous ice-induced vibrations on the JZ20-2MUQ and JZ9-3 platforms also reduced the comfort and work efficiencies of the operators and even led to serious harm to their physical and mental health. In such cases, sea ice management is needed as an important means to ensure the operational security of oil and gas platforms in winter.

International sea ice management is a comprehensive system that contains a variety of means and technologies. Sea ice monitoring, risk warning, emergency measures and other means are primarily used to analyze and evaluate the threats caused by sea ice and ensure production safety. For the establishment and improvement of sea ice management 
systems in different environment, international scholars have done a lot of work on the research of sea ice management. Joakim Haugen et al.[3] describe a framework of an ice observer system for aiding decisions regarding risk assessment of the ice environment, and present Unmanned Aerial Vehicles (UAVs) as a viable sensor platform for dynamic positioning systems. Risto Haimelin et al.[4] discusse the risks in ice management operations caused by uncertainties arising in the light of novel risk perspectives, and define an ice management system. Charles C. Ryerson[5] provides a review of ice protection strategies for functional platform areas and suggests a framework for assessing the relative threat of ice accumulation types.

The mainstream international methods for ice management are listed in Table 1.

Tab. 1. Main ice management methods

\begin{tabular}{|c|c|c|}
\hline Sea ice monitoring & Risk prediction & Emergency measure \\
\hline $\begin{array}{l}\text { satellite } \\
\text { aircraft } \\
\text { image sensor } \\
\text { sea-based radar } \\
\text { sonar } \\
\text { Autonomous } \\
\text { Underwater Vehicle }\end{array}$ & $\begin{array}{l}\text { evaluation of sea } \\
\text { ice parameters } \\
\text { meteorological } \\
\text { and hydrological } \\
\text { parameter } \\
\text { evaluation } \\
\text { threat rating }\end{array}$ & $\begin{array}{l}\text { water cannons } \\
\text { icebreaker }\end{array}$ \\
\hline
\end{tabular}

In the Barents Sea, Russian scientists have recorded large amounts of iceberg data using observation aircraft and ice breaking ships since the 1930s[6]. The data can be used to show the direction, size and distribution of icebergs in the area. The typical sea ice detection methods are shown in Fig. 1.

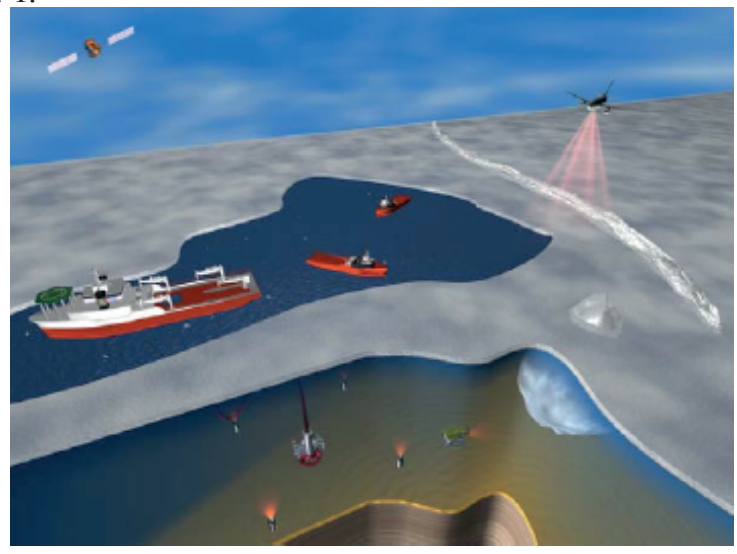

Fig. 1. Typical sea ice detection methods used throughout the world

In the Beaufort Sea, a set of sea ice management systems was established from 1983 to 1993 to mitigate the influence of sea ice on oil and gas exploration and included ice monitoring, ice early warning, ice alarm and icebreaker command systems[7]. The monitoring system was primarily used to monitor the movement and melting of sea ice, the early warning system classified the sea ice threat into different degrees to provide targeted emergency measures, and the command system commanded and dispatched icebreakers to protect the drilling facilities to reduce the threat of sea ice to the project.

As sea ice in different regions demonstrate the characteristics of their respective. Benefit from the monitoring data, the principle, risk prediction and emergency measure of sea ice management have made progress. Andrew R. Mahoney et al.[8] suggest that the differences in the timing of the annual landfast ice cycle are largely through analysis of over 2500 synthetic aperture radar (SAR) scenes spanning the period 1996-2008 in the Chukchi and Beaufort Seas. Kenneth Eik et al. $[9,10]$ present methodologies for both systematic evaluation of the need for the iceberg management system and structural reliability based on the experiences from the Canadian iceberg detection studies. By tracking of 9 icebergs and 10 ice floes in the Kanumas area of the Greenland Sea during 2012-2014, Renat Yulmetov et al.[11] proposes an iceberg drift model including the rotation. Robert S. Pritchard et al.[12] present a blended mechanistic-statistical ice motion model for shortterm forecasts by virtue of an investigation of coherent ice drift features associated with individual ice beacons during winter 2008. J.V. Lukovich et al.[13] has provided an ice drift case study analysis relevant to, and template for, highresolution sea ice dynamic modeling studies essential for safety and hazard assessments of transportation routes and shipping lanes, ice forecasting, and nutrient and contaminant transport by sea ice in the Arctic.

For the icebergs threat of oil exploitation on the eastern coast of Canada, McClintock[14] proposed a complete set of technologies for iceberg detection and tracking. Rudkin[15] also proposed a complex set of methods for evaluating the effectiveness of dragging an iceberg.

In the Bohai Sea, which is a typical marginal oil field, most of the offshore oil and gas platforms are economical platforms set in a seasonally frozen region for cost savings, which is unique, uncertain and carries great risk; there is no global precedent for this. Due to the large quantity and difference in ages and structural forms, each platform in Bohai has its own characteristics and anti-ice capacity. To date, existing technologies are mainly aimed at the observation and forecasting of sea ice features and cannot meet the risk warning accuracy and timeliness requirements of oil and gas platforms. In the field of international engineering development in cold regions, there are no monitoring and safety management systems for oil and gas exploitation. It is therefore necessary to build a risk prediction and emergency system for the Bohai Sea in winter.

\section{OIL AND GAS EXPLOITATION AND SEA ICE MANAGEMENT IN BOHAI}

China began oil exploration and development in Bohai in the 1960s, and more than one hundred offshore platforms have 
been built there. Because the water depths generally range from $10-30 \mathrm{~m}$ and due to the nature of marginal offshore oilfield exploitation, most of the platforms are jacket platforms. Bohai lies between 37 degrees and 41 degrees north latitude. As a seasonally frozen region, it generally begins to freeze in December and melts during the following March. The glacial period lasts for approximately 2-3 months, and the longest period can be 4 months or more. The maximum volume of ice can be up to $60-70 \mathrm{~km} 3$. The threats caused by sea ice greatly influence oil and gas drilling, exploitation and transportation in Bohai. Historically, sea ice has caused many accidents on platforms and spawned great economic losses. Ice has become the most threatening factor for the oil platforms in Bohai Bay when compared with wind, ocean waves, currents, tides, and earthquakes.

Because the general design life of a jacket platform is 15-20 years, most of the platforms in Bohai are currently close to the end of their service lives. Although maintenance costs are high, the owners still want to extend the service life of the platforms on the oil-reservoir waters due to economics. In addition, at the time these platforms were designed, the research on sea ice was limited; the ice loads were not clearly understood, and the ice-resistant capabilities of these platforms are therefore poor.

Fig. 2 shows a typical jacket platform in Bohai Bay. Early field monitoring of an individual platform found severe iceinduced vibrations in Bohai[16]. Through long-term and continuous monitoring, it was concluded that the structures of the jacket platforms in Bohai are slender in comparison to deep-sea wave-resistant structures and that ice-induced vibrations can cause node fatigue failure of structures, the functional failure of facilities and influence workers' health[17]. The vibration problems of platforms caused by dynamic ice forces are far greater than the overall safety risks under extreme loads.

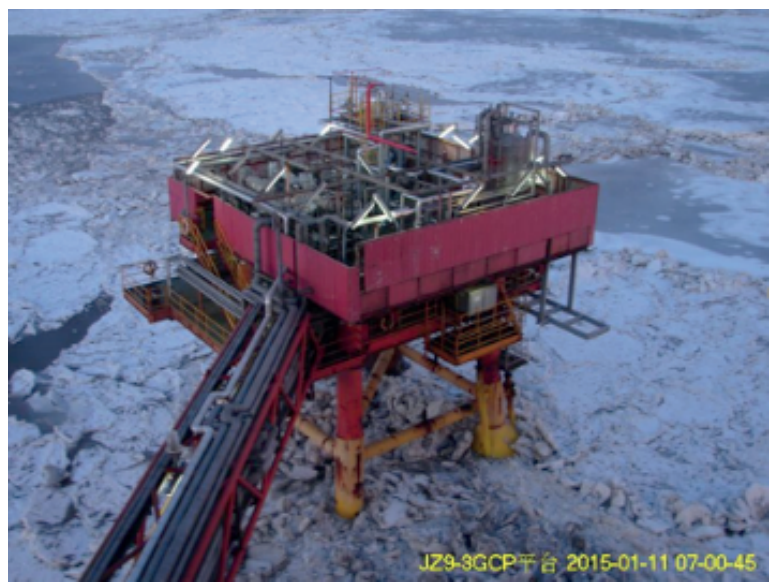

Fig. 2. Typical jacket platform in Bohai Bay

Yue et al. researched sea ice disasters involving oil and gas platforms in Bohai since the late 1980s. In the preliminary research stage, the monitoring of ice-induced vibrations lacked direction due to a vague understanding of the associated problems. Most ice load research studied the interactions between sea ice and platform structures. Ice force was measured on the jacket platform using a pressure box. In addition, there was an undefined understanding of sea ice management. Because the interaction between sea ice and platform structure is especially influenced by environmental conditions, as the research continued, targeted environment parameters, including winds, waves, currents and temperature, were monitored. A preliminary real-time sea ice monitoring system was then built based on the integrated application of meteorological observation stations, wireless network equipment, radars, cameras, current meters and other means.

A complete sea ice management system has been established based on years of field monitoring and research. Ice resistant platform security has been gradually developed, and structure analyses and an evaluation system have been introduced.

\section{BOHAI OIL AND GAS PLATFORM SEA ICE MANAGEMENT TECHNOLOGY}

Based on research on theories of how sea ice disasters develop and the failure modes of ice-induced vibrations, ice vibration risk levels and early warning standards have been advanced, and a real-time safety evaluation system for oil and gas platforms has been established. For the purpose of developing risk warnings for oil and gas exploitation in the Bohai Sea in winter, a set of monitoring systems has been developed that realizes a synchronous, real-time remote approach to monitoring using wireless transmission technology and creates an Internet database. Finally, risk prediction and emergency technologies were developed, and a Monitoring - Evaluation - Early warning - Emergency measure management mode was built based on the environmental characteristics of Bohai. The management consists of the following parts.

\section{(1) Structural risk monitoring technology}

Sea ice field monitoring is the primary purpose of the safety system in winter. Information on sea ice, platform structure and upper pipeline system is obtained using the monitoring technology to provide a basis for safety evaluations of the platform systems. On the other hand, the monitoring data will form the basis of sea ice prediction and risk warnings.

(2) Structure risk evaluation technology

For the threats that ice-resistant platforms face in cold regions, the ice-induced vibration failure modes and discrimination indexes of the ice-resistant jacket platforms are determined by mechanical analyses to evaluate the security of the platforms in real time and effectively take emergency measures.

\section{Early warning standards and emergency measures}

Because accurate sea ice predictions are critical to ensure production safety in winter, a method that combines numerical and statistical predictions has been presented to 
forecast the generation, disappearance and movement of sea ice. Based on the sea ice predictions, the ice forces and iceinduced vibrations are obtained by further analyses. In this manner, the safety level of a platform system can be predicted over the next 24 or 48 hours.

The above three parts are complementary and together compose the security system.

\section{SEA ICE MONITORING TECHNOLOGY}

Utilizing advanced sensors and data acquisition equipment, sea ice monitoring systems can monitor the risk factors of platforms without interruption, which enables monitoring at any time. In addition, with the aid of computer systems, monitoring data can be processed and analyzed.

Using the MUQ JZ20-2 platform as an example (see Fig. 3), sea ice field monitoring systems for oil and gas platforms in Bohai should include all information that can indicate failures and include three monitoring systems: sea ice, environmental and structural response. Sea ice monitoring data are the requisite information for evaluating platform security and include thickness, velocity, distribution, and ice type. A video sensor is used to monitor the sea ice in the sea area of the platform, and the software shown in Fig. 4 is used to analyze ice thickness, velocity and concentration. The monitoring of sea ice environmental factors is mainly accomplished by monitoring meteorology and hydrology. A weather station is used to record wind velocity, water temperature and other meteorological parameters. The structural vibration response monitoring is divided into two parts: platform vibration monitoring and sea ice force monitoring. Acceleration was selected as the measurement parameter for structural vibration, and an acceleration sensor is used to record the platform vibrations. In addition, a pressure box is used to measure the sea ice force acting on the structure.

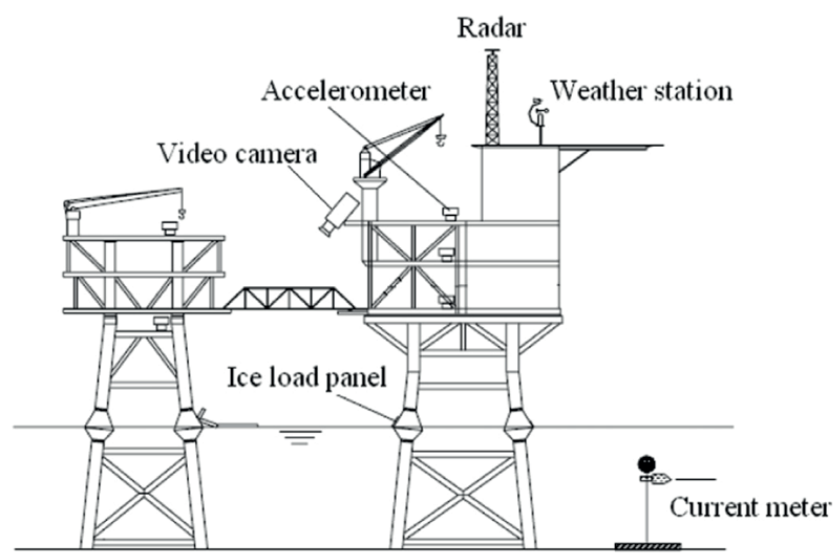

Fig. 3. Bohai oil and gas platform sea ice monitoring system

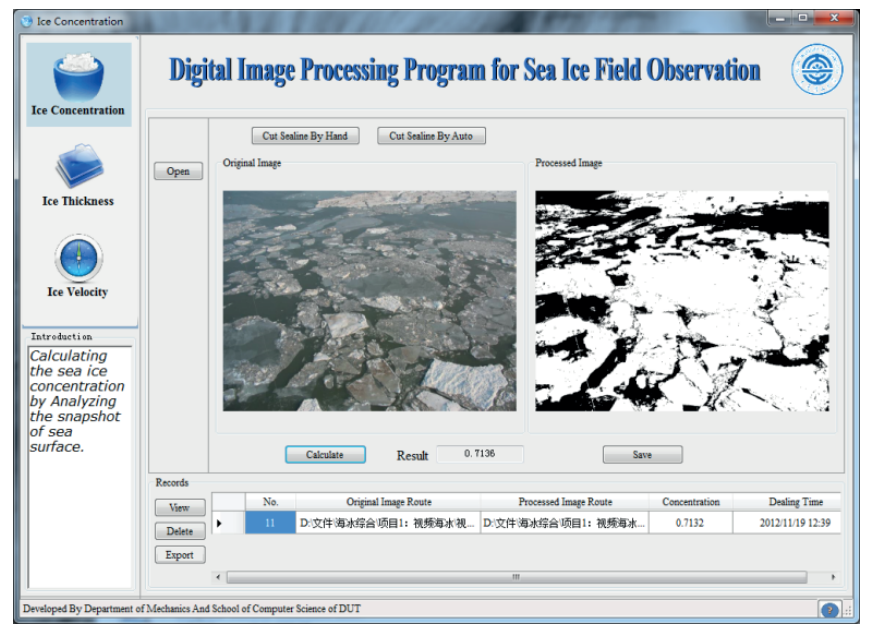

Fig. 4. Sea ice image measurement software

As a marginal field, the oil fields in Bohai are scattered. Because the marine environments differ, the monitoring content in different areas differs. To conveniently manage the monitoring data on the platforms, a multi-information synchronization measurement system was established. This system applies wireless transmission technology to achieve the real-time control, monitoring and collection of the data from each platform. A typical measurement system is shown in Fig. 5.

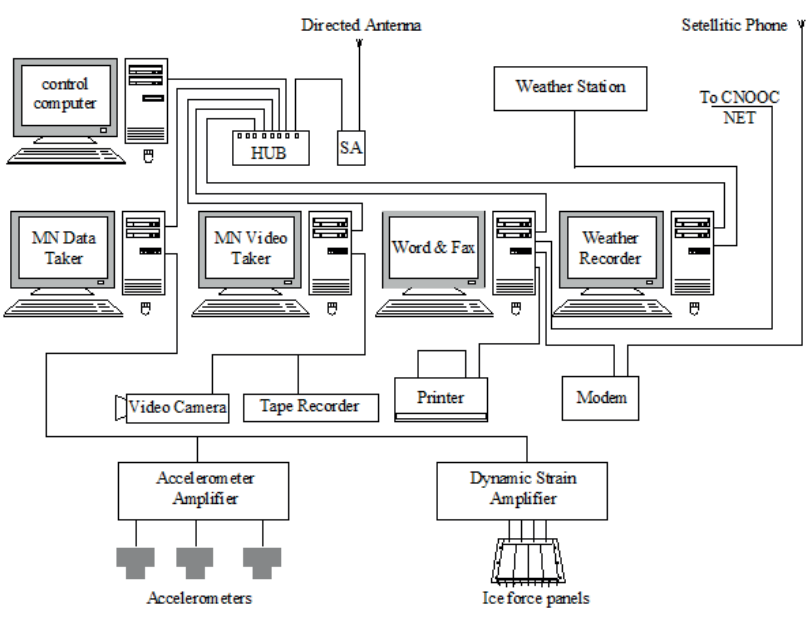

Fig. 5. Ice detection and ice-induced vibration measurement system

In the Bohai, the system uses the MUQ JZ20-2 platform (center platform) as the relay node, which is connected to the Internet via satellite. The controlling terminal on land communicates with the field monitoring network through the Internet, so that the field monitoring data can be transmitted to the controlling terminal's server on land over the network, and the land controlling terminal can also access the data in real-time. Using this system, the field monitoring data will be automatically transferred to the control center's server on land, and experts can offer rational suggestions by inspecting the measured data. As shown in Fig. 6, the operations at each 
center are interactive so that the monitoring of the risk factors can be synchronous, real-time and remotely accomplished.

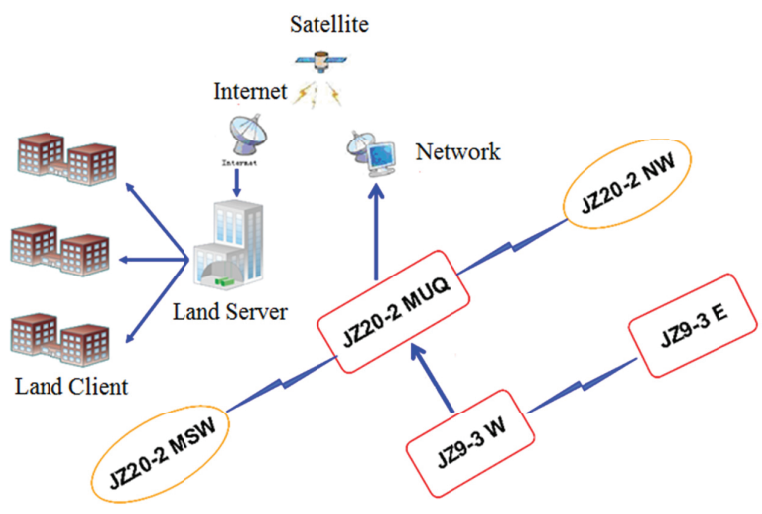

Fig. 6. Multi-platform Internet monitoring system

\section{SEA ICE RISK ANALYSIS AND EVALUATION TECHNOLOGY}

The sea ice risk safety evaluation system for oil and gas platforms in Bohai is based on the field monitoring data. This system defines the failure modes and quantitative failure indicators of the platforms under sea ice loads, analyzes quantitatively the failure of the ice resistant platforms by numerical simulation, and establishes the different degrees of warning standards for different ice-resistant platforms. As shown in Fig. 7, based on the above methods, risk classification and assignment of the corresponding risk grades for the Bohai platforms are conducted.

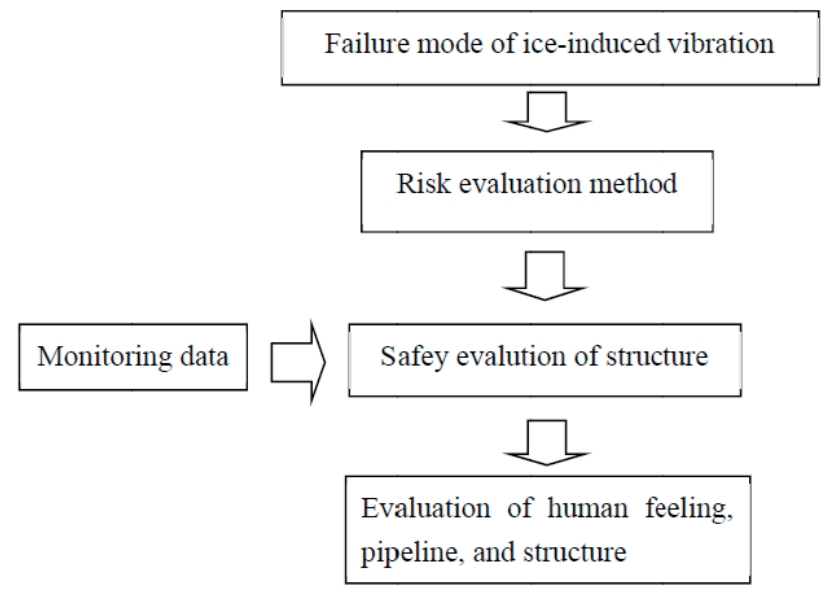

Fig. 7. Platform risk safety evaluation system

The main risk evaluation criteria for ice-resistant offshore jacket platforms should involve the following three parts:
(1) Structural safety evaluation. Include structural damage caused by exceeding the limits of deformation or strength under extreme ice forces and structural fatigue caused by dynamic ice loads.

(2) Personnel comfort evaluation. Deck vibrations caused by dynamic ice forces cause operators to feel unwell, which leads to inefficiencies when working and even damage to health.

(3) Platform facility evaluation. Under the action of dynamic ice forces, strong continuous platform vibrations cause pipeline fractures and flanges to loosen, which affects facility operations.

The above risk evaluations and corresponding criteria are shown in Table 2.

Tab. 2 Evaluation criteria of platform risks in cold regions

\begin{tabular}{|c|c|c|}
\hline Failure type & Performance description & $\begin{array}{c}\text { Failure } \\
\text { discrimination } \\
\text { index }\end{array}$ \\
\hline \multirow{2}{*}{ 苞 } & $\begin{array}{c}\text { Structural safety damage } \\
\text { under extreme static ice loads }\end{array}$ & $\begin{array}{c}\text { Structural } \\
\text { deformation or } \\
\text { strength }\end{array}$ \\
\hline & $\begin{array}{l}\text { Structural fatigue damage } \\
\text { under dynamic ice loads }\end{array}$ & $\begin{array}{l}\text { Cyclical stress of } \\
\text { tubular joints }\end{array}$ \\
\hline 胥 & $\begin{array}{l}\text { Physical discomfort, } \\
\text { degraded work efficiency, and } \\
\text { even endangered health of } \\
\text { the crew members induced } \\
\text { by deck vibrations }\end{array}$ & $\begin{array}{l}\text { Equivalent deck } \\
\text { acceleration, } \\
\text { frequency, duration, } \\
\text { and direction }\end{array}$ \\
\hline 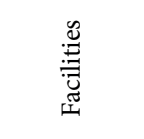 & $\begin{array}{l}\text { Unserviceability or damage } \\
\text { to facilities on the platforms } \\
\text { induced by intensive deck } \\
\text { vibrations }\end{array}$ & $\begin{array}{l}\text { Equivalent deck } \\
\text { acceleration }\end{array}$ \\
\hline
\end{tabular}

According to the above risk evaluations and corresponding criteria, the contents of each failure type specifically related to the risk are divided as follows.

(1) Structural security hazard

The Jz20-2 offshore platform, which is composed by 3 platforms (Jz20-2MUQ, Jz20-2MSW and Jz20-2NW), is used as an example. The frequencies, ultimate displacements and limiting accelerations of the platforms are listed in Table 3:

Tab. 3 Maximum values for the Jz20-2 platform

\begin{tabular}{|c|c|c|c|}
\hline & $\begin{array}{c}\text { Frequency } \\
(\mathrm{Hz})\end{array}$ & $\begin{array}{c}\text { Maximum } \\
\text { displacement } \\
(\mathrm{mm})\end{array}$ & $\begin{array}{c}\text { Maximum } \\
\text { acceleration } \\
\left(\mathrm{m} / \mathrm{s}^{2}\right)\end{array}$ \\
\hline Jz20-2MUQ & 1.17 & 168 & 9.06 \\
\hline Jz20-2MSW & 1.44 & 130 & 10.63 \\
\hline Jz20-2NW & 1.01 & 118 & 4.74 \\
\hline
\end{tabular}

For each platform, the security of the structure can be judged by comparing the displacements or accelerations of the platform with the limiting values to avoid damaging effects 
from sudden sea ice disasters. Considering the complex characteristics of the sea ice and platform structures in Bohai, Yue Q.J. [18] proposed a fatigue analysis process based on research on the ice-induced fatigue problem (as shown in Fig. 8). On that basis, Zhang D.Y.[19] put forward a method for estimating ice-induced fatigue life based on field monitoring data to evaluate fatigue damage to platforms, employing the method in combination with numerical analysis.

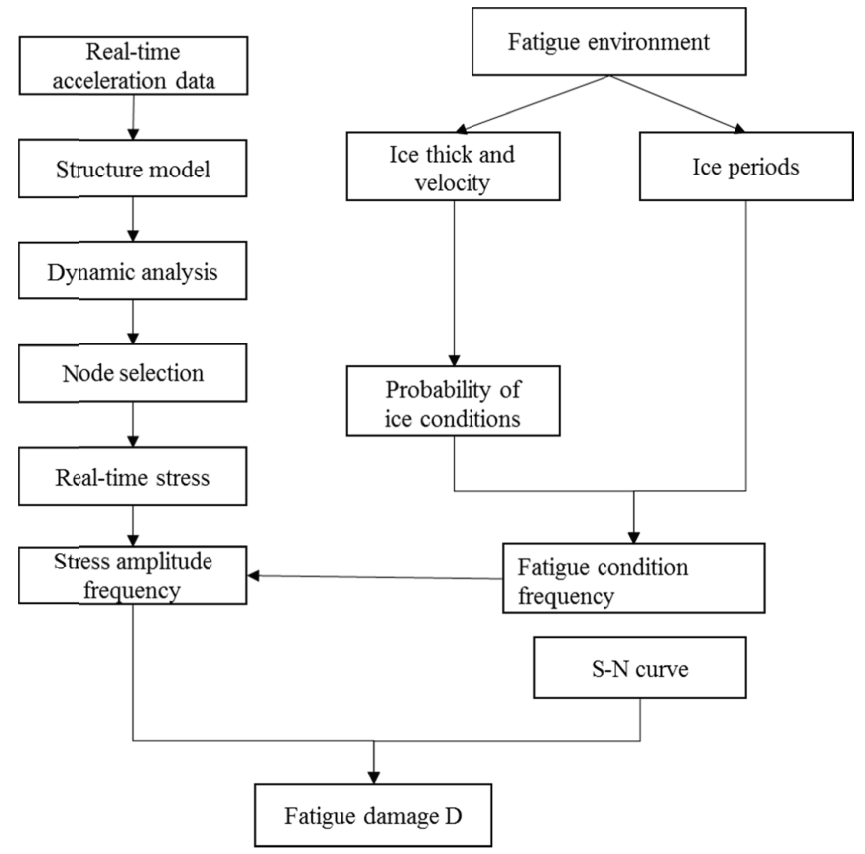

Fig. 8. Time-domain fatigue analysis flow chart

(2) Influence of personnel comfort

The influence of vibrations on the human body is mainly related to vibrational frequency, the root mean square value of acceleration, duration and direction. Because the vibration frequencies of offshore platforms are mainly focused at $1 \mathrm{~Hz}$ and are horizontal, referring to the Chinese national standard (GB/T 13442-92) of the regulation on the less than $2 \mathrm{~Hz}$ vibration index, the relationship between the root mean square value and exposure time becomes clarified, and the standard has been defined at three levels: comfort reduction, work efficiency reduction and exposure limit (as shown in Table 4). By combining the root mean square values of the critical acceleration of each stage with the measured values, human responses can be evaluated in real time.

Tab. 4. Acceleration root mean square limits for humans undergoing horizontal vibrations (units: $\mathrm{m} / \mathrm{s}^{2}$ )

\begin{tabular}{|c|c|c|c|c|c|c|c|c|c|}
\hline & $\stackrel{f}{\underset{d}{d}}$ & $\underset{0}{0}$ & $\frac{5}{\infty}$ & F & $\underset{\substack{n \\
\mathrm{n}}}{\mathrm{L}}$ & 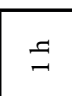 & $\begin{array}{l}\text { 吉 } \\
\text { L } \\
\stackrel{n}{n}\end{array}$ & $\begin{array}{l}\stackrel{\Xi}{\Xi} \\
\text { b }\end{array}$ & $\underset{\Xi}{\text { 寻 }}$ \\
\hline I & 0.03 & 0.05 & 0.07 & 0.11 & 0.16 & 0.27 & 0.40 & 0.48 & 0.63 \\
\hline II & 0.095 & 0.158 & 0.221 & 0.347 & 0.504 & 0.851 & 1.260 & 1.512 & 1.985 \\
\hline III & 0.19 & 0.316 & 0.442 & 0.694 & 1.008 & 1.702 & 2.52 & 3.024 & 3.97 \\
\hline
\end{tabular}

(I- comfort reduction, II- reduction in work efficiency, III-exposure limit)

(3) Impact on platform facilities

Under strong ice-induced vibrations, fractures and loosening are much more likely to occur on platform pipelines and flanges. Based on years of deck and pipeline vibration monitoring and research on Bohai oil and gas platforms, it can be considered that the root mean square value of the deck acceleration is the main parameter to judge the vibrational circumstances of pipelines and flanges. The failures can be divided into three cases: minor damage, flange loosening and pipeline fractures, as shown in Table 5. Evaluations and analyses of vibration conditions are then based on actual measurement data, and real-time warnings therefore can be implemented.

Tab. 5. Acceleration root mean square limits for pipelines undergoing horizontal vibrations units $\left(\mathrm{m} / \mathrm{s}^{2}\right)$

\begin{tabular}{|c|c|c|}
\hline & Status & Maximum RMS acceleration \\
\hline I & minor damage & arms $<0.4$ \\
\hline II & flange loosening & $0.4<$ arms $<1.04$ \\
\hline III & pipeline fractures & arms $>0.4$ \\
\hline
\end{tabular}

\section{RISE PREDICTION AND EMERGENCY MEASURES}

The accurate prediction of sea ice conditions and risk warnings for oil and gas exploitation are necessary for safe production on oil platforms in Bohai. Using the method of combined numerical and statistical forecasting, a risk warning model for oil and gas exploitation in Bohai has been developed, as shown in Fig. 9. Based on the weather and hydrological predictions and initial ice conditions, sea ice is predicted, ice forces and the ice-induced vibrational responses of different platforms are further analyzed, the safety grade of the platform system is predicted over the next 24 or 48 hours and timely emergency measures are taken.

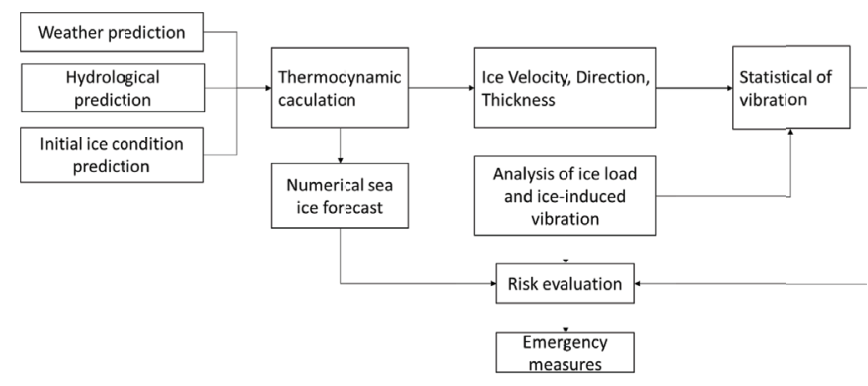

Fig. 9 Risk forecasting and warning system

(1) Sea ice prediction

Sea ice prediction is among the key factors for predicting ice loads and platform vibrational responses. Numerical 


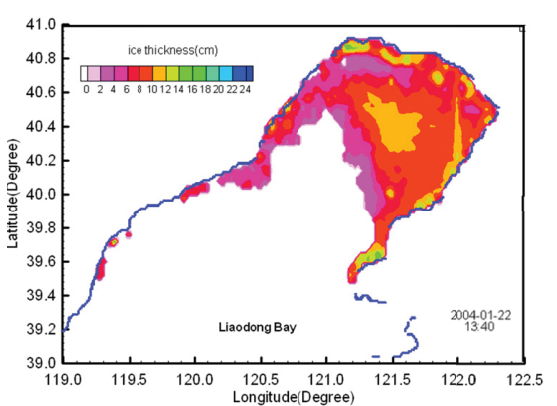

(a)

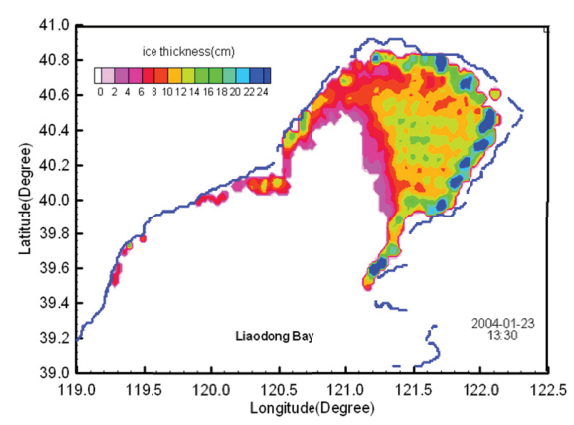

(c)

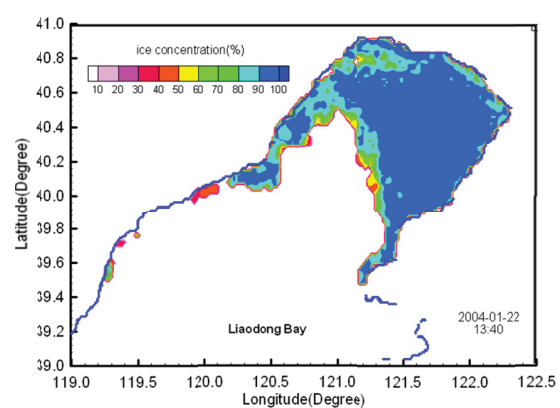

(b)

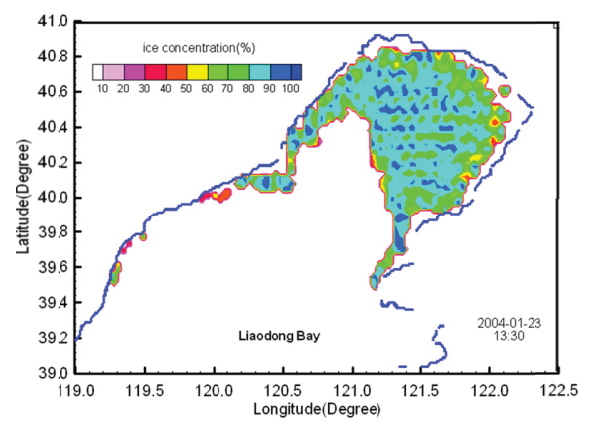

(d)

(a) Initial ice thickness distribution, (b) Initial ice intensity distribution, (c) Ice thickness distribution after 24 hours and (d) Ice intensity distribution after 24 hours

Fig. 10. Numerical prediction of sea ice

prediction models are usually used when making predictions based on sea ice and monitoring meteorological and hydrological data. Ji S.Y.[20] established a visco-elasticplastic constitutive model for sea ice dynamics and developed a numerical method that combines Euler and Lagrange coordinates to improve numerical prediction accuracy. The numerical prediction model transforms satellite images into binary images to determine sea ice edge lines and ice concentrations. Comparing a gray image with monitoring data ensures the relationship between ice thickness and gray value. Finally, the initial sea ice distribution data are obtained. Referencing the meteorological and hydrological changes in the last 24 hours, such as shown in Fig. 10, the thickness and density of the sea ice are predicted. Initial ice thickness and initial ice intensity distributions are shown in Figures 10 (a) and (b), and ice thickness and ice intensity distributions after 24 hours are shown in Figures 10 (c) and (d).

Through numerical simulation, sea ice conditions can be obtained directly. However, the numerical simulation accuracies can be influenced by many factors, including the initial sea ice field, calculation parameters, thermodynamic factors, and computing mode. Especially in the extreme and changing climate, the numerical prediction method may encounter great difficulties when considering the conversion processes of sea ice types. The statistical prediction of sea ice elements is an empirical prediction method whereby the regularity of the motion and evolution of sea ice in areas near oil platforms, including weather conditions, sea ice types, and hydrological conditions, are summarized. Based on the monitoring data, the following conclusions are drawn. (i) Meteorological conditions

The influence of wind on ice conditions should be considered when north winds reach magnitudes exceeding 5 .

Ice conditions would be reduced by south winds, and the influence on ice conditions would not be considered when the wind is southerly.

For temperatures below -6 , ice conditions generally worsen.

\section{(ii) Sea ice type}

The platforms have been less affected by broken sea ice but have been significant impacted by whole pieces of sea ice.

The influence on the platforms should be considered for nilas ice, pancake ice, gray ice or gray-white sea ice types and for thicknesses exceeding 10-12 cm.

\section{(iii) Hydrological Conditions}

In general, the danger caused by sea ice usually occurs during periods of ebb tides and when the velocity exceeds $40 \mathrm{~cm} / \mathrm{s}$.

Other dangerous moments are at 18:00-23:00 and 0:004:00, at high tide.

Ice-induced vibrations do not occur when sea waves are above moderate.

\section{(2) Ice-induced vibration response prediction}

The prediction of ice-induced structure vibrations is based on method that combines dynamic calculations and statistical analysis. The intensities of ice-induced vibrations 
on platform are decided by three factors (ice velocity, ice thickness and ice breaking strength). Because the breaking strength of ice varies little within a sea area, ice condition can be described by ice velocity and thickness. Although the ice velocity and the ice thickness distributions are unrelated stochastic processes, ice condition can be described by a combination of ice velocity and ice thickness. The acceleration response of a deck under different ice conditions (shown in Fig. 12) is calculated using a finite element model (shown in Fig. 11).

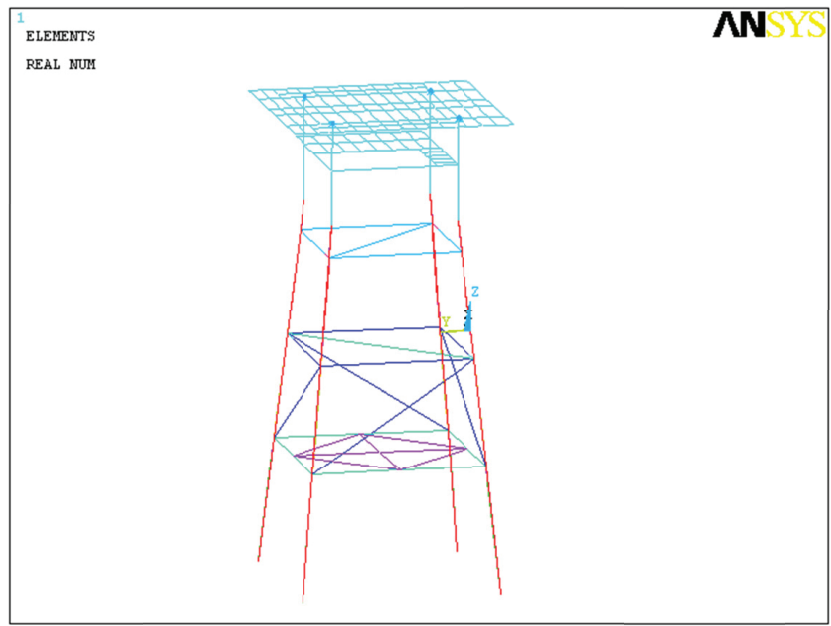

Fig. 11. Finite element model of $J z 9-3 G C P$

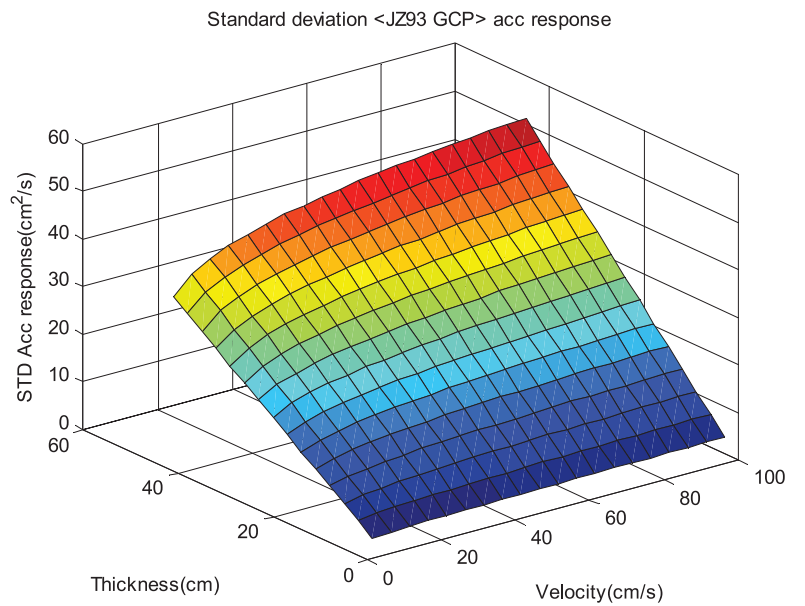

Fig. 12. Maximum acceleration of the JZ93-GCP platform under different ice conditions

Using the above methods, platform vibration response can be predicted based on the sea ice predictive parameters and research on the interactions between ice and structure, and the sea ice risk can then be evaluated.

According to a statistical analysis of ice acceleration data, the relationship between ice acceleration and ice velocity has been confirmed to be linear under certain ice thickness conditions. Based on the ice-induced vibration monitoring data from 2009 to 2013, Fig. 13 shows the analyzed relationship between the root mean square values of the acceleration of the JZ20-2MUQ platform and nearby ice thickness, and Fig. 14 shows the analyzed relationships between the maximum acceleration and the velocity and ice thickness.

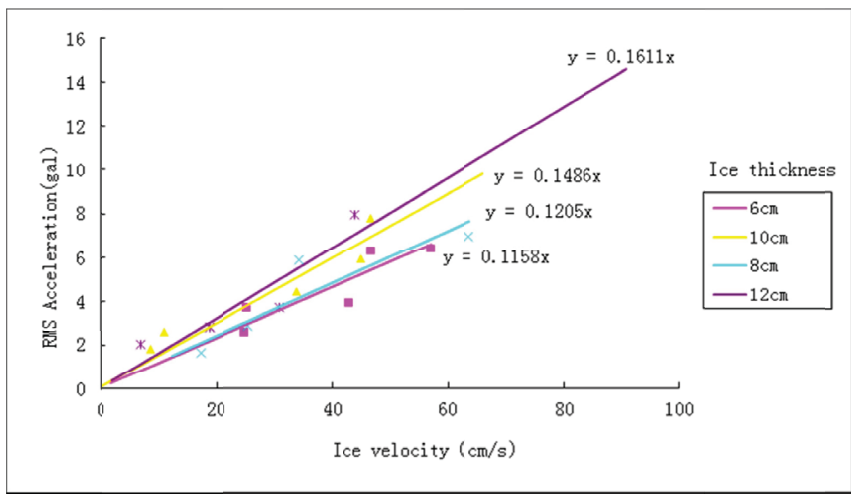

Fig. 13. The relationships between the root mean square value of the acceleration and the ice thickness

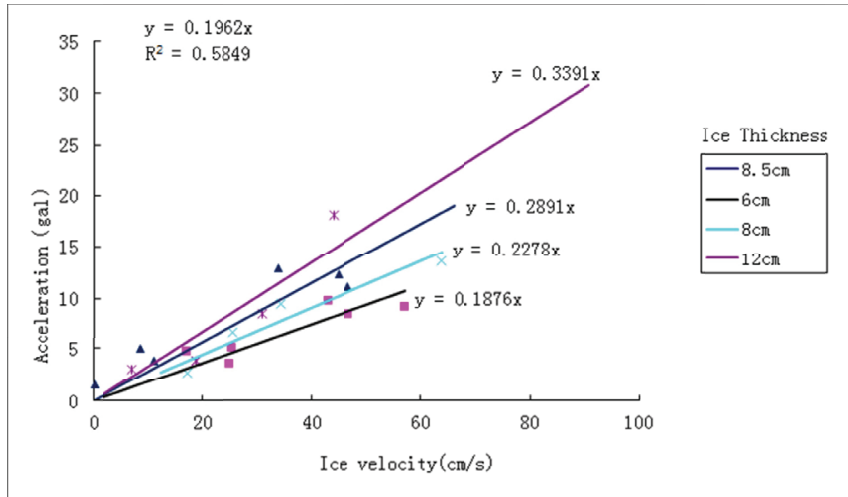

Fig. 14. The relationships between the maximum acceleration and the velocity and ice thickness

Based on the monitoring data, the linear relations between the ice-induced vibrations and the ice thickness and ice velocity were statistically established. The relations can be expressed as

$$
a=\alpha \cdot h_{\mathrm{i}}^{2} \cdot v_{\mathrm{i}}
$$

where $\mathrm{a}$ is the acceleration (gal) of the structure, $\alpha$ is an undetermined coefficient, $h_{\mathrm{i}}$ is the ice thickness $(\mathrm{cm})$, and $v_{\mathrm{i}}$ is the ice velocity $(\mathrm{cm} / \mathrm{s})$.

According to the above statistics, the $\alpha$ for predicting acceleration on the JZ20-2MUQ platform under different ice thickness conditions are given by formula 3-1 and are shown in Table 6. 
Tab. 6. The coefficients of different ice thicknesses from JZ20-2MUQ

\begin{tabular}{|c|c|}
\hline$h_{i}$ & $a$ \\
\hline $6 \mathrm{~cm}$ & 0.00521 \\
\hline $8 \mathrm{~cm}$ & 0.00370 \\
\hline $10 \mathrm{~cm}$ & 0.00289 \\
\hline $12 \mathrm{~cm}$ & 0.00236 \\
\hline
\end{tabular}

The monitoring data for Jz20-2MUQ from 2014 to 2015 were used to validate the model. The predicted and measured values of the ice-induced vibrations of the JZ20-2MUQ platform under different ice conditions are shown in Table 7.

Tab. 7. Predicted and measured values for the JZ20-2MUQ platform

\begin{tabular}{|c|c|c|c|}
\hline 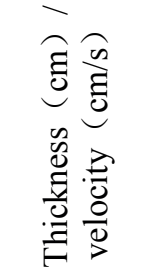 & 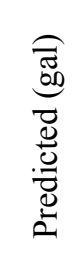 & 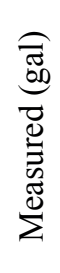 & 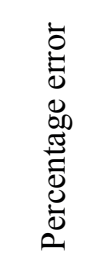 \\
\hline $4.5 / 9$ & 1.16 & 1 & $16 \%$ \\
\hline $5.5 / 9$ & 1.52 & 1.5 & $1.3 \%$ \\
\hline $6.5 / 9$ & 1.84 & 2 & $8 \%$ \\
\hline $7 / 12.5$ & 2.73 & 2.5 & $9.2 \%$ \\
\hline $8.5 / 27.5$ & 6.94 & 7.5 & $7.4 \%$ \\
\hline $9 / 17.5$ & 4.67 & 5 & $6.6 \%$ \\
\hline $10 / 17.5$ & 5.06 & 4.8 & $5.4 \%$ \\
\hline $11.5 / 22.5$ & 7.41 & 6 & $23.5 \%$ \\
\hline
\end{tabular}

Table 7 shows that the predicted results were close to the measured values, with errors of $5.4 \%$ to $23.5 \%$. The statistical forecast model can satisfy the demands of engineering applications.

\section{(3) Risk prediction and emergency measures}

Based on years of sea ice monitoring data and practical experience, the quantitative indexes for safe production on platforms (e.g., early warning of dangerous time, platform warning suggestions, and icebreaker management) should be proposed for risk prediction and emergency measures to make 24-hour short-term predictions for the platforms. The early warnings for times of danger primarily include weather, ice type and hydrological condition forecasts. As shown in Fig. 15, the platform warning suggestions intended for potential risk predictions for the platforms include personnel health and facility and structural safety for the next 24 hours. Icebreaker management manages icebreaker dispatches, icebreaking directions and icebreaking ranges.

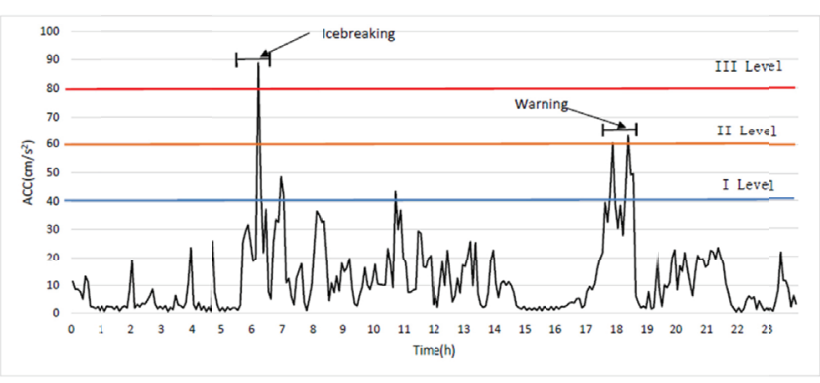

Fig. 15. 24-hour risk predictions

The management of icebreakers is divided into three levels: enhanced monitoring without icebreakers (level I), increased numbers of icebreakers on duty (level II), and breaking the ice a half hour prior to danger (level III).

\section{CONCLUSIONS}

In this paper, for the purpose of risk warnings for oil and gas exploitation in the Bohai Sea in winter, an ice-induced vibration risk system for platforms has been established, iceinduced vibration risk grades and early warning standards for platforms have been formulated, and a dynamic evaluation system for sea ice disasters for platform security has been put forward.

Based on the ice-induced vibration failure modes and early warning standards of the platforms, a dynamic monitoring system for ice-resistant platforms has been established. The system can monitor the risk factors synchronously, remotely and in real time using developed mass data transmission and analysis software. After years of application, the system has proven to be stable and durable.

Based on a small-scale numerical simulation and prediction method for sea ice, an ice condition prediction and risk early warning system has been built for the Bohai oil and gas platforms. The sea ice disaster risk early warning system for the oil field and emergency technologies have been applied and incorporated into practical engineering.

Sea ice management for oil and gas platforms guarantees the security of life and property in Bohai and brings large economic and social benefits. The system also significantly offers field-monitoring data for ice-resistant structure designs in cold regions.

\section{ACKNOWLEDGEMENTS}

The support of the National Natural Science Foundation of China (51679033, 51309046), State's Key Project of Research and Development Plan (2016YFC0303400), the Special items of national marine public welfare industry (201505019) are much appreciated. 


\section{REFERENCES}

1. Engelbrekston A.: Dynamic ice loads on lighthouse structures, Proc.4th Int. Conf. on Port and Oc. Engrg. under Arctic Conditions, St. John's Canada, 1977, 2:p.654-864.

2. Määttänen M, Reddy D, Arockiasamy M, et al.: Icestructure interaction studied on a lighthouse in the Gulf of Bothnia using response spectrum and power spectral density function analyses. Proc.4th International Conference on Port and Ocean Engineering under Arctic Conditions Newfoundland, Canads. 1977, p.321-334.

3. J Haugen, L Imsland, S Loset, R Skjetne.: Ice Observer System for Ice Management Operations, Proceedings of the Twenty-first (2011) International Offshore and Polar Engineering Conference, 2011, p.1120-1127.

4. R Haimelin, F Goerlandt, P Kujala, B Veitch.: Implications of novel risk perspectives for ice management operations. Cold Regions Science \& Technology, No 1, Vol.133, 2016, p.82-93.

5. Charles C. Ryerson.: Ice protection of offshore platforms. Cold Regions Science and Technology, No 1, Vol.65, 2011, p.97-110.

6. ABRAMOV, Valentin A.: Russian iceberg observations in the Barents Sea, 1933-1990. Polar Research, No 2, Vol.11, 1992, p.93-97.

7. Eik, K.: Review of experiences within ice and iceberg management. Journal of Navigation, No4, Vol.61, 2008, p. 557-572.

8. AR Mahoney, H Eicken, AG Gaylord, R Gens.: Landfast sea ice extent in the Chukchi and Beaufort Seas the annual cycle and decadal variability. Cold Regions Science \& Technology, No 1, Vol.103, 2014, p.41-56.

9. K Eik, OT Gudmestad.: Iceberg management and impact on design of offshore structures. Cold Regions Science \& Technology, No 1-2, Vol.63, 2010, p.15-28.

10. K Eik.: Sea-ice management and its impact on the design of offshore structures. Cold Regions Science \& Technology, No 2, Vol.65, 2011, p.172-183.

11. Renat Yulmetov, Aleksey Marchenko, Sveinung Loset.: Iceberg and sea ice drift tracking and analysis off northeast Greenland. Ocean Engineering, No 1, Vol.123, 2016, p.223-237.

12. Robert S. Pritchard, Guang Li, R.O Davis.: A deterministicstatistical sea ice drift forecast model. Cold Regions Science and Technology, No 1, Vol.s76-77, 2011, p.52-62.
13. JV Lukovich, C Bélanger, DG Barber, Y Gratton.: On coherent ice drift features in the southern Beaufort sea. Deep Sea Research Part I Oceanographic Research Papers, No 10, Vol.92, 2014, p.56-74.

14. McClintock J, Bullock T, McKenna R., Ralph F and Brown R.: Greenland Iceberg Management: Implications for Grand Banks Management Systems. PERD/CHC Report, 2002, p.20-65.

15. Rudkin P, Boldrick C and Barron Jr P.: PERD Iceberg Management Database. PERD/CHC Report, 2005, p.20-72.

16. Duan Menglan, Fang Huacan.: The survey conclusions of Bohai second platform was pulled down by Ice. Oil Field Equipment, No 3,Vol.23, 1994, p.1-4.

17. Yue Qianjin, Bi Xiangjun.: Ice-induced jacket structure vibrations in Bohai Sea. Journal of Cold Regions Engineering, No.2, Vol.14, 2001, p.81-92.

18. Yue Qianjin, Zhang Dayong, Liu Yuan, Tong Baolin.: Failure modes analysis of ice-resistant compliant structures based on monitoring oil platforms in Bohai Gulf. The Ocean Engineering, No 1, Vol.26, p.18-23.

19. Zhang Dayong.: Performance based on risk design research of ice-resistant jacket structures. Dalian University of Technology, 2007.

20. Ji Shunying, Shen Hongdao, Wang Zhilian, Xi Meili, Yue Qianjin.: Dynamics sea ice constitutive model of viscoelastic plastic based on Mohr-Coulomb criterion. Acta Oceanologica Sinica, No 4, Vol.27, 2005, p.19-30.

\section{CONTACT WITH THE AUTHOR}

ZHANG Da-yong, Prof. Dr. e-mail: zhangdy@dlut.edu.cn

School of Ocean Science \& Technology Dalian University of Technology Panjin

CHINA 